\title{
ANALISIS ANTREAN DAN KINERJA SISTEM PELAYANAN GARDU TOL OTOMATIS GERBANG TOL MUKTIHARJO (Studi Kasus: Gardu Tol Otomatis Gerbang Tol Muktiharjo)
}

\author{
Erna Fransisca Angela Sihotang ${ }^{1}$, Sugito ${ }^{2}$, Moch. Abdul Mukid ${ }^{3}$ \\ 1,2,3 Departemen Statistika FSM Universitas Diponegoro \\ ernaefa@gmail.com
}

\begin{abstract}
Queue process is a process related to the arrival of customers in a service facility, waiting in line queue if it cannot be served, get service and finally leaves the facility after being served. Research on the queue process can be seen directly through the queue system at the automatic toll booth Muktiharjo. Queue models and their distribution were obtained using the Sigma Magic program. The model of the vehicle queue system at the Muktiharjo Automatic Toll Gate is $(\mathrm{GAMM} / \mathrm{GAMM} / 4)$ : $(\mathrm{GD} / \infty / \infty)$. Based on the values of the queue system performance measures obtained through the MATLAB GUI program as a whole it can be concluded that the queue of vehicles at the Muktiharjo Automatic Toll Gate has a condition where the average number of vehicles estimated in the system every 15 minutes is 25,5646 vehicles. The average number of vehicles in the queue system every 15 minutes is 24,5639 vehicles. The waiting time in the system is estimated to be around 7,99332 seconds. The estimated waiting time in line is around 7,68042 seconds. The queue system has a busy opportunity of $63.2849 \%$ and the remaining $36.7106 \%$ is a chance the queue system is not busy. The simulation of the vehicle queue system at the Automatic Toll Gate of Muktiharjo Toll Gate by using ARENA is optimal with the number of service points as many as 4 automatic toll booths.
\end{abstract}

Keywords: Automatic Toll Booth, Queue, Gamma Distribution, Performance Size, Queue Simulation

\section{PENDAHULUAN}

Pertumbuhan kendaraan di Indonesia mengalami kenaikan jumlah setiap tahun. Hal ini dipengaruhi oleh pertumbuhan manusia saat ini. Berdasarkan proyeksi Badan Perencanaan Pembangunan Nasional 2013, jumlah penduduk Indonesia pada 2018 mencapai 265 juta jiwa. Meningkatnya populasi manusia di Indonesia mengakibatkan kebutuhan transportasi yang semakin meningkat setiap tahunnya. Berdasarkan Badan Pusat Statistik pada tahun 2017, tercatat bahwa ada sebanyak 15.493 .068 mobil, 2.509.258 bis, dan 7.523.550 kendaraan barang. Ketidakseimbangan populasi manusia dengan fasilitas teknologi kerap menimbulkan antrean dalam penggunaan fasilitas teknologi umum. Kemunculan teori antrean dipicu oleh masalah keterbatasan kapasitas pelayanan untuk melayani permintaan pelanggan (Siswanto, 2006). Proses antrean sendiri merupakan suatu proses yang berhubungan dengan kedatangan pelanggan pada suatu fasilitas pelayanan, menunggu dalam baris antrian jika belum dapat dilayani, dilayani dan akhirnya meninggalkan fasilitas tersebut sesudah dilayani.

Meningkatnya penggunanaan jalan yang digunakan untuk setiap alat transportasi di Indonesia mengakibatkan banyak kemacetan. Untuk mendukung gerak pertumbuhan ekonomi, Indonesia membutuhkan jaringan jalan yang handal. Melalui Peraturan Pemerintah No. 04 Tahun 1978, pada tanggal 01 Maret 1978 Pemerintah mendirikan PT Jasa Marga (Persero) Tbk. Pemberlakuan pembayaran secara tunai dilakukan dengan baik oleh PT Jasa Marga, namun saat ini penggunaan transaksi secara tunai mulai berubah ke penggunaan transaksi nontunai. Gerbang Tol Muktiharjo adalah gerbang tol 
yang memberikan fasilitas Gardu Tol Otomatis untuk kendaraan yang datang dari arah Pelabuhan Semarang, Demak dan Kudus. Banyaknya kendaraan yang datang pada saat tertentu dan kurangnya informasi yang dimiliki para pengendara mengenai Gardu Tol Otomatis bisa menyebabkan antrean yang berkepanjangan. Cara untuk mengetahui kinerja pelayanan gardu tol otomatis adalah melakukan analisis sistem antrean dan kinerja sistem pada gardu tol otomatis serta melakukan simulasi sistem antrean. Hasil analisis akan dijadikan kajian untuk pengambilan keputusan pengembangan sistem antrean gardu tol yang efektif untuk masa mendatang.

\section{TINJAUAN PUSTAKA}

\subsection{Profil Umum Jasa Marga}

Jasa Marga adalah Badan Usaha Milik Negara Indonesia yang bergerak di bidang penyelenggara jasa jalan tol. PT Jasa Marga (Persero) Tbk didirikan pada tanggal 1 Maret 1978 melalui Peraturan Pemerintah No. 4 Tahun 1978. Pendirian PT Jasa Marga didirikan dengan tujuan untuk mendukung gerak pertumbuhan ekonomi Indonesia. Tugas utama Jasa Marga adalah merencanakan, membangun, mengoperasikan dan memelihara jalan tol serta sarana kelengkapannya agar jalan tol dapat berfungsi sebagai jalan bebas hambatan yang memberikan manfaat lebih tinggi daripada jalan umum bukan tol. Gerbang Tol Muktiharjo adalah gerbang tol yang memberikan fasilitas Gardu Tol Otomatis untuk kendaraan yang datang dari arah Pelabuhan Semarang, Demak dan Kudus (Jasamarga Semarang, 2018).

\subsection{Deskripsi Antrean}

Menurut Kakiay (2004), Antrean adalah suatu garis tunggu dari sejumlah pelanggan yang memerlukan pelayanan dari satu atau lebih fasilitas pelayanan. Proses antrean adalah suatu proses yang berhubungan dengan kedatangan pelanggan pada suatu fasilitas pelayanan, menunggu dalam baris antrean jika belum dapat dilayani, dilayani dan akhirnya meninggalkan fasilitas tersebut sesudah dilayani.

\subsection{Faktor Sistem Antrean}

Menurut Kakiay (2004), terdapat beberapa faktor penting yang berpengaruh terhadap barisan antrean dan pelayanannya dengan sistem antrean yaitu distribusi kedatangan, distribusi waktu pelayanan, fasilitas pelayanan, disiplin antrean, ukuran dalam antrean dan sumber pemanggilan.

\subsection{Struktur Dasar Sistem Antrean}

Menurut Subagyo et al. (1992), ada empat model struktur antrean dasar yang umum terjadi dalam seluruh sistem antrean, antara lain:

1. Satu Antrean Satu Pelayanan (Single Channel-Single Phase)

Dalam sistem ini hanya ada satu jalur masuk sistem pelayanan dan hanya terdapat satu fasilitas pelayanan. Setelah mendapat pelayanan pelanggan akan keluar dari sistem. Contoh untuk struktur ini adalah pembelian tiket kereta api yang dilayani oleh satu loket.

2. Satu Antrean, Beberapa Pelayanan Seri (Single Channel-Multiphase)

Pada sistem ini menunjukkan hanya terdapat satu jalur masuk sistem pelayanan dan terdapat dua atau lebih fasilitas pelayanan secara seri dalam jalur tersebut. Contoh untuk struktur ini adalah pada pencucian mobil.

3. Satu Antrean Beberapa Pelayanan Paralel (Multichannel-Single Phase) 
Pada sistem ini menunjukkan terdapat dua atau lebih jalur masuk sistem pelayanan dan hanya terdapat satu fasilitas pelayanan dalam setiap jalurnya. Contoh untuk struktur model ini adalah pembelian tiket yang dilayani oleh lebih dari satu loket pelayanan.

4. Beberapa Antrean Beberapa Pelayanan Paralel (Multichannel-Multiphase)

Pada sistem ini terdapat dua atau lebih jalur masuk sistem pelayanan dan juga terdapat dua atau lebih fasilitas pelayanan secara seri dalam setiap jalurnya. Contohnya pada herregistrasi mahasiswa.

\subsection{Notasi Kendall}

Menurut Kakiay (2004) bentuk kombinasi proses kedatangan dengan pelayanan pada umumnya dikenal sebagai standar universal, yaitu: (a/b/c) : (d/e/f). Dengan simbol $\mathrm{a}, \mathrm{b}, \mathrm{c}, \mathrm{d}$, e dan $\mathrm{f}$ merupakan unsur-unsur dasar dari model baris antrean. Penjelasan dari simbol-simbol di atas adalah sebagai berikut:
a : Distribusi kedatangan (arrival distribution).
b : Distribusi waktu pelayanan (service time distribution).
c : Jumlah tempat pelayanan (dengan $\mathrm{c}=1,2,3, \ldots \infty)$.
d : Disiplin pelayanan misalkan FIFO, LIFO, SIRO, PS.
e : Jumlah maksimum pelanggan yang diizinkan dalam sistem.
f : Sumber pemanggilan.

\subsection{Ukuran Steady State}

Steady state merupakan kondisi sewaktu sifat-sifat sistem tidak berubah dengan berjalannya waktu. Dalam kondisi steady state, diharapkan bahwa rata-rata pelanggan yang datang memiliki nilai yang sebanding dengan rata-rata pelanggan yang telah dilayani atau dapat dikatakan rata-rata pelanggan yang datang tidak melebihi rata-rata pelanggan yang telah dilayani $(\lambda<\mathrm{c})$, sehingga jika $\rho<1$ maka dapat diartikan memenuhi kondisi steady state.

\subsection{Proses Poisson dan Distribusi Eksponensial}

Theorema I (Gross dan Harris, 1998)

Untuk suatu proses Poisson, jumlah kedatangan terjadi pada interval waktu $t$ adalah variabel acak yang mengikuti distribusi Poisson dengan rata-rata $\lambda t$ dan probabilitas dari n kedatangan adalah $P_{n}(t)=\frac{(\lambda t)^{-n} e^{-\lambda t}}{n !}$

Theorema 2 (Gross dan Harris, 1998)

Jika jumlah kedatangan mengikuti distribusi Poisson maka suatu variabel random waktu antar kedatangan mengikuti distribusi Eksponensial. Jika kedatangan mengikuti proses Poisson dengan parameter $\lambda$, maka suatu variabel acak berturutan akan mengikuti distribusi Eksponensial dengan parameter $\frac{1}{\lambda}$

\subsection{Uji Kecocokan Distribusi}

Untuk mengetahui bentuk-bentuk fungsi dari populasi yang diteliti, maka langkah pertama yang dilakukan adalah menguji apakah populasi tersebut memiliki kecenderungan untuk terdistribusi sesuai dengan asumsi-asumsi yang mendasari prosedur parametrik yang diusulkan. Menurut Daniel (1989), apabila sampel yang ditarik dari populasi-populasi yang tidak diketahui, maka digunakan metode-metode keselarasan untuk menentukan sampel seberapa jauh data sampel yang teramati cocok dengan model yang ditawarkan. Uji-uji keselarasan bisa menjadi alat yang bermanfaat 
untuk mengevaluasi sampai seberapa jauh suatu model mampu mendekati situasi nyata yang digambarkannya. Terdapat dua metode keselarasan yang paling umum digunakan, yaitu uji keselarasan Kolmogorov-Smirnov dan uji Kai-Kuadrat. Adapun langkahlangkah penentuan distribusi adalah sebagai berikut:

\subsubsection{Uji Kolmogorov Smirnov}

a. Menentukan Hipotesis

$\mathrm{H}_{0}$ : Distribusi sampel mengikuti distribusi yang ditetapkan

$\mathrm{H}_{1}$ : Distribusi sampel tidak mengikuti distribusi yang ditetapkan

b. Menentukan Taraf Signifikansi

Taraf signifikansi yang digunakan adalah $\alpha=5 \%$

c. Statistik Uji

$$
D=\sup _{x}\left|S(x)-F_{0}(x)\right|
$$

dengan:

$\mathrm{S}(\mathrm{x})$ : fungsi peluang kumulatif yang dihitung dari data sampel

$\mathrm{F}_{0}(\mathrm{x})$ : fungsi distribusi yang dihipotesiskan (fungsi peluang kumulatif)

d. Kriteria Uji

Tolak $\mathrm{H}_{0}$ jika pada taraf signifikansi $\alpha$ jika nilai $\mathrm{D} \geq$ nilai $\mathrm{D}_{\text {tabel }}(1-\alpha)$ atau jika nilai sig $<$ nilai $\alpha$. $\mathrm{D}_{\text {tabel }}(\alpha)$ adalah nilai kritis yang diperoleh dari tabel Kolmogorov-Smirnov.

\subsubsection{Uji Chi Square}

a. Menentukan hipotesis

$\mathrm{H}_{\mathrm{o}}$ : Sampel yang telah ditarik dari sebuah populasi yang mengikuti suatu distribusi yang ditetapkan

$\mathrm{H}_{1}$ : Sampel bukan berasal dari populasi dengan distribusi yang ditetapkan

b. Menentukan taraf signifikansi

Taraf signifikansi yang digunakan adalah $\alpha=5 \%$

c. Statistik Uji

$$
\chi^{2}=\sum_{i=1}^{k} \frac{(O i-E i)^{2}}{E i}
$$

Dengan Oi adalah Frekuensi-frekuensi yang teramati, Ei adalah frekuensifrekuensi harapan serta i dan $\mathrm{k}$ adalah kategori

e. Kriteria Uji

Menolak $\mathrm{H}_{\mathrm{o}}$ pada taraf signifikansi $\alpha$ apabila nilai $\chi^{2} \geq \chi^{2}{ }_{\alpha, v}$ dengan $\mathrm{v}=\mathrm{r}-1-\mathrm{g}$ atau $\mathrm{p}$-value $<\alpha$ dimana $\mathrm{g}$ adalah jumlah parameter distribusi yang ditetapkan dan $\mathrm{r}$ adalah jumlah kelas)

\subsection{Distribusi Gamma}

Menurut Walpole \& Myers (1995), Peubah acak kontinu X berdistribusi Gamma, dengan parameter $\alpha$ dan $\beta$, bila fungsi kepadatan peluangnya berbentuk $\mathrm{f}(\mathrm{x})$

$$
f(x)= \begin{cases}\frac{1}{\beta^{\alpha} \Gamma(\alpha)} x^{\alpha-1} e^{-\frac{x}{\beta}} & , x>0 \\ 0 & \text {, lainnya }\end{cases}
$$

dengan $\alpha>0$ dan $\beta>0$, dimana $\alpha=\frac{\mu}{\beta}$ dan $\beta=\frac{\frac{1}{n} \sum_{i=1}^{n}\left(x_{i}-\mu\right)^{2}}{\mu}$

Fungsi gamma didefinisikan sebagai

$\Gamma(\alpha)=\int_{0}^{\infty} x^{\alpha-1} e^{-x} d x$ 
untuk $\alpha>0$

Rataan dan variansi distribusi gamma adalah

$$
\begin{aligned}
& \mu=\alpha \beta \\
& \sigma^{2}=\alpha \beta^{2}
\end{aligned}
$$

\subsection{Model-Model Sistem Antrean}

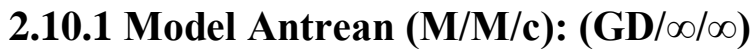

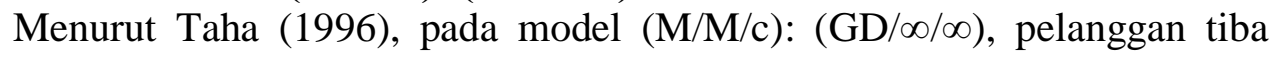
dengan laju konstan, maksimum $c$ pelanggan dapat dilayani secara bersamaan, dan laju pelayanan per pelayanan adalah konstan. Pengaruh dari penggunaan $c$ pelayanan yang pararel adalah mempercepat laju pelayanan dengan memungkinkan dilakukannya beberapa pelayanan secara bersamaan. Jika jumlah pelanggan dalam sistem adalah $n$ sama dengan atau lebih besar dari $c$, maka laju keberangkatan gabungan dari sistem tersebut adalah $c \mu$. Jika $n$ lebih kecil dari $c$, maka laju pelayanannya $n \mu$. Jadi dalam bentuk model yang digeneralisasi diperoleh rumus berikut

$$
\begin{aligned}
& \lambda_{n}=\lambda, n \geq 0 \\
& \mu_{n}=\left\{\begin{array}{l}
n \mu, n \leq c \\
c \mu, n \geq c
\end{array}\right.
\end{aligned}
$$

Karena itu, menghitung Pn untuk $n \leq c$ sebagai

$$
P_{n}=\frac{\lambda^{n}}{\mu(2 \mu)(3 \mu) \ldots(n \mu)} P_{0}=\frac{\lambda^{n}}{n ! \mu^{n}} P_{0}
$$

untuk $n \geq c$

$$
P_{n}=\frac{\lambda^{n}}{\mu(2 \mu) \ldots(c-1) \mu(c \mu)(c \mu) \ldots(c \mu)} P_{0}=\frac{\lambda^{n}}{c ! c^{n-c} \mu^{n}} P_{0}
$$

Jika dianggap bahwa $\rho=\frac{\lambda}{\mu}$, nilai $\mathrm{P}_{0}$ ditentukan dari $\sum_{n=0}^{\infty} P_{n}=1$ yang memberikan

$$
\begin{aligned}
& P_{0}=\left\{\sum_{n=0}^{c-1} \frac{\rho^{n}}{n !}+\frac{\rho^{c}}{c !} \sum_{n=c}^{\infty} \frac{\rho^{n-c}}{c^{n-c}}\right\}^{-1} \\
& =\left\{\sum_{n=0}^{c-1} \frac{\rho^{n}}{n !}+\frac{\rho^{c}}{c !} \sum_{j=0}^{\infty}\left(\frac{\rho}{c}\right)^{j}\right\}^{-1} \\
& =\left\{\sum_{n=0}^{c-1} \frac{\rho^{n}}{n !}+\frac{\rho^{c}}{c !}\left(\frac{1}{1-\frac{\rho}{c}}\right)\right\}^{-1}, \frac{\rho}{c}<1
\end{aligned}
$$


Jadi, $P_{n}=\left\{\begin{array}{l}\left(\frac{\rho^{n}}{n !}\right) P_{0}, 0 \leq n \leq c \\ \left(\frac{\rho^{n}}{c^{n-c} c !}\right) P_{0}, n>c\end{array}\right.$

Rumus untuk mencari ukuran-ukuran kinerja pada model antrean (M/M/c):

$(\mathrm{GD} / \infty / \infty)$ adalah sebagai berikut:

$$
\begin{aligned}
L q & =\frac{\rho^{c+1}}{(c-1) !(c-\rho)^{2}} P o \\
L s & =L q+\rho \\
W q & =\frac{L q}{\lambda} \\
W s & =W q+\frac{1}{\mu}
\end{aligned}
$$

\subsubsection{Model Antrean (G/G/c): (GD/ $/ \infty)$}

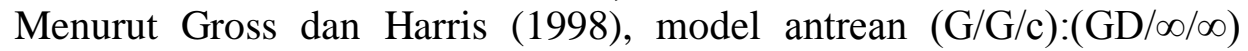
adalah model antrean dengan pola kedatangan berdistribusi umum (general) dan pola pelayanan berdistribusi umum (general) dengan jumlah fasilitas pelayanan sebanyak $c, c=1,2,3, \ldots$. Disiplin antrean yang digunakan pada model ini adalah umum yaitu FIFO (First In First Out), kapasitas maksimum yang diperbolehkan dalam sistem adalah tak hingga, dan memiliki sumber pemanggilan tak hingga. Untuk penghitungan jumlah pelanggan yang diperkirakan dalam antrean $\left(L_{q}\right)$ didasarkan pada ukuran kinerja pada model $(\mathrm{M} / \mathrm{M} / \mathrm{c}):(\mathrm{GD} / \infty / \infty)$. Rumus untuk mencari ukuran-ukuran kinerja pada model $(\mathrm{G} / \mathrm{G} / \mathrm{c}):(\mathrm{GD} / \infty / \infty)$ adalah sebagai berikut :

$L q=\frac{\rho^{c+1}}{(c-1) !(c-\rho)^{2}} \operatorname{Po} \frac{\mu^{2} v(t)+v\left(t^{\prime}\right) \lambda^{2}}{2}$

dengan:

$v(t)$ adalah varian dari waktu pelayanan

$v\left(t^{\prime}\right)$ adalah varian dari waktu antar kedatangan

$L s=L q+\rho$

$W q=\frac{L q}{\lambda}$

$W s=W q+\frac{1}{\mu}$

\subsection{Simulasi Sistem}

Menurut David Kelton (2004), simulasi mengacu pada metode dan aplikasi untuk menirukan perilaku sistem yang sesungguhnya. Simulasi sudah banyak diterapkan pada banyak bidang industri. Pemecahan masalah dengan model simulasi biasanya dilakukan dengan memakai komputer, sebab banyak perhitungan yang terlalu rumit dihitung dengan tangan. Perbedaan distribusi dalam tingkat pelayanan jauh lebih mudah diadopsi di dalam model dibandingkan dengan tingkat kedatangan. Hal ini dapat diatasi dengan menggunakan simulasi (Siswanto, 2007). 


\subsection{Graphic User Interfaces (GUI) MATLAB}

Menurut Arhami et.al (2005) MATLAB (Matrix Laboratory) adalah sebuah program untuk analisis dan komputasi numerik, merupakan suatu bahasa pemrograman matematika lanjutan yang dibentuk dengan dasar pemikiran menggunakan sifat dan bentuk matriks. Matlab banyak digunakan pada matematika dan komputasi, pengembangan dan algoritma, pemrograman model, simulasi, analisa data, eksplorasi, visualisasi dan pengembangan aplikasi teknik.

\section{METODE PENELITIAN}

Data yang digunakan dalam penulisan penelitian ini adalah data primer, yaitu data yang diperoleh dengan pengamatan dan pencatatan langsung dari obyek penelitian. Penelitian dilakukan dengan mengambil sampel data selama 5 hari. Penelitian dilaksanakan di Gardu Tol Otomatis Gerbang Tol Muktiharjo dengan waktu pelaksanaan pada tanggal 17 Desember 2018 sampai dengan tanggal 21 Desember 2018. Penelitian dilakukan mulai pukul 07.00 WIB sampai dengan pukul 17.00 WIB setiap harinya. Alat yang digunakan untuk melakukan pencatatan waktu kedatangan kendaraan dan lamanya waktu pelayanan adalah software Xnote Stopwatch yang terhubung langsung dengan Microsoft Excel 2010. Sementara output yang dihasilkan merupakan hasil pengolahan data dengan menggunakan software Statistika, yaitu IBM SPSS Statistics 22, Sigma Magic, GUI MATLAB, dan ARENA. Langkah-langkah analisis yang digunakan pada penelitian ini adalah sebagai berikut:

1. Menentukan tempat penelitian dan metode penelitian. Melakukan penelitian secara langsung di Gardu Tol Otomatis Gerbang Tol Muktiharjo untuk mendapatkan data jumlah kendaraan yang datang dan data jumlah kendaraan yang dilayani.

2. Data yang diperoleh harus memenuhi kondisi steady-state $\left(\rho=\frac{\lambda}{c \mu}<1\right)$, dengan $\lambda$ sebagai rata-rata kedatangan kendaraan dan $\mu$ sebagai rata-rata kendaraan yang telah dilayani.

3. Melakukan uji kecocokan distribusi untuk kedatangan dan pengunjung terlayani dengan menggunakan uji Kolmogorov Smirnov. Jika hipotesis untuk distribusi jumlah kedatangan dan jumlah pelayanan diterima maka distribusinya mengikuti distribusi Poisson dan apabila hipotesisnya ditolak maka distribusi kedatangannya berdistribusi General.

4. Menentukan model antrean yang sesuai. Dilihat dari distribusi kedatangan, distribusi pelayanan, banyaknya jumlah pelayanan, disiplin antrean yang digunakan adalah First In First Out (FIFO) kapasitas dalam sistem dan sumber pemanggilan.

5. Membuat Simulasi Antrian .

6. Menentukan kinerja sistem, yaitu jumlah pelanggan yang diperkirakan dalam sistem (Ls), jumlah pelanggan yang diperkirakan dalam antrean (Lq), waktu menunggu dalam sistem (Ws), dan waktu menunggu dalam antrean (Wq).

7. Membuat hasil dan pembahasan.

8. Mengambil kesimpulan mengenai pelayanan di Gardu Tol Otomatis Gerbang Tol Muktiharjo secara keseluruhan.

4. HASIL DAN PEMBAHASAN

4.1. Gambaran Umum Sistem Antrean Kendaraan di Gardu Tol Otomatis Gerbang tol Muktiharjo 
Gerbang Tol Muktiharjo adalah gerbang tol yang memberikan fasilitas Gardu Tol Otomatis untuk kendaraan yang datang dari arah Pelabuhan Semarang, Demak dan Kudus.

\subsection{Deskripsi Data}

Data yang digunakan adalah data jumlah kendaraan yang datang dan jumlah kendaraan yang dilayani pada pelayanan Gardu Tol Otoatis Gerbang Tol Muktiharjo. Jumlah data yang digunakan adalah sebagai berikut:

Tabel 1. Data jumlah kendaraan yang datang dan dilayani

\begin{tabular}{ccc}
\hline Hari & Jumlah Kendaraan yang Datang & Jumlah Kendaraan yang Dilayani \\
\hline Senin & 6.859 & 6.851 \\
Selasa & 7.099 & 7.098 \\
Rabu & 7.683 & 7.679 \\
Kamis & 7.870 & 7.866 \\
Jumat & 8.868 & 8.860 \\
Total & 38.379 & 38.354 \\
\hline
\end{tabular}

\subsection{Analisis Antrean Gardu Tol Otomatis Gerbang Tol Muktiharjo}

\subsubsection{Ukuran Steady State}

Kondisi steady state terpenuhi jika nilai tingkat kegunaan $(\rho)<1$ artinya rata-rata jumlah kendaraan yang datang lebih kecil dari rata-rata jumlah kendaraan yang dilayani. Untuk menghitung nilai $\rho$ tersebut perlu diketahui nilai rata-rata jumlah kendaraan yang datang dan rata-rata jumlah kendaraan yang dilayani. Interval waktu yang digunakan adalah 15 menit.

1. Rata-rata jumlah kendaraan yang datang $(\lambda)$ adalah 191,90 kendaraan tiap 15 menit.

2. Rata-rata jumlah kendaraan yang dilayani $(\mu)$ adalah 191,77 kendaraan tiap 15 menit.

3. Jumlah gardu tol otomatis pelayanan pada Gerbang Tol Muktiharjo adalah 4.

Tabel 2. Tingkat Kegunaan Fasilitas Pelayanan Gardu Tol Otomatis Gerbang Tol Muktiharjo

\begin{tabular}{cccc}
\hline $\mathrm{c}$ & $\lambda$ & $\mu$ & $\rho=\frac{\lambda}{c \mu}$ \\
\hline 4 & 191,895 & 191,77 & 0,250162956
\end{tabular}

Dari Tabel 2, dapat diketahui bahwa nilai tingkat kegunaan fasilitas pelayanan Gardu Tol Otomatis Gerbang Tol Muktiharjo kurang dari satu maka disimpulkan bahwa sistem antrean steady state.

\subsubsection{Uji Distribusi}

Uji kecocokan distribusi yang digunakan untuk menguji data jumlah kendaraan yang datang dan jumlah pelayanan kendaraan adalah uji Kolmogorov Smirnov. Pada uji tersebut akan diketahui apakah data jumlah kendaraan yang datang dan jumlah kendaraan yang dilayani berdistribusi Poisson.

Tabel 3. Uji Distribusi Berdasarkan Output SPSS

\begin{tabular}{cccc}
\hline Data & D hitung $_{\text {Jumlah Kendaraan }}$ & D tabel $_{1}$ & Keputusan \\
yang Datang & $\sup _{x}\left|S(x)-F_{0}(x)\right|=$ & $\frac{1,36}{\sqrt{200}}=0,096166522$ & $\mathrm{H}_{0}$ ditolak \\
\hline
\end{tabular}




\begin{tabular}{|c|c|c|c|}
\hline & 0,270 & & \\
\hline $\begin{array}{l}\text { Jumlah Kendaraan } \\
\text { yang Dilayani }\end{array}$ & $\begin{array}{c}\sup _{x}\left|S(x)-F_{0}(x)\right|= \\
0,256\end{array}$ & $\frac{1,36}{\sqrt{200}}=0,096166522$ & $\mathrm{H}_{0}$ ditolak \\
\hline
\end{tabular}

Jadi, pada taraf signifikansi 5\% didapatkan hasil bahwa data jumlah kendaraan yang datang dan jumlah kendaraan yang dilayani di Gardu Tol Otomatis Gerbang Tol Muktiharjo tidak berdistribusi Poisson atau berdistribusi General.

\subsubsection{Model Sistem Antrean}

Tabel 4. Penentuan Model Distribusi Berdasarkan Output Magic Sigma

\begin{tabular}{|c|c|c|}
\hline Data & Statistik Uji & Keputusan \\
\hline Jumlah Kendaraan yang Datang & $\chi^{2}=\sum_{i=1}^{k} \frac{(O i-E i)^{2}}{E i}=10,497$ & \\
& $p$-value $=0,725$ & $\mathrm{H}_{0}$ diterima \\
\hline Jumlah Kendaraan yang Dilayani & $\begin{array}{c}\chi^{2}=\sum_{i=1}^{k} \frac{(O i-E i)^{2}}{E i}=8,74 \\
p \text {-value }=0,847\end{array}$ & $\mathrm{H}_{0}$ diterima \\
\hline
\end{tabular}

Berdasarkan Tabel 4, model sistem antrean dengan distribusi jumlah kendaraan yang datang adalah Gamma dan distribusi jumlah kendaraan yang dilayani adalah Gamma, dengan fasilitas pelayanan sebanyak 4, disiplin antrean yang digunakan adalah yang pertama datang yang pertama dilayani (FIFO), serta jumlah kapasitas pelanggan yang datang dan sumber pemanggilan tidak terbatas.

\subsubsection{Simulasi Sistem Antrean}

Simulasi dilakukan untuk mengetahui gambaran langsung mengenai pelayanan Gardu Tol Otomatis di Gerbang Tol Muktiharjo jika terdapat tempat pelayanan sebanyak 2 gardu, 3 gardu, 4 gardu dan 5 gardu. Proses simulasi dilakukan dengan menggunakan software ARENA dengan diberi masukan parameter ditribusi Gamma dalam penyusunan gambar simulasi. Adapun parameter jumlah kendaraan yang datang adalah $\beta=9,691$ dan $\alpha=19,802$ serta parameter jumlah kendaraan yang dilayani adalah $\beta=9,7771$ dan $\alpha=19,6142$ Proses simulasi dilakukan dengan replikasi sebanyak 10 kali dengan ekspresi distribusi adalah GAMM(beta, alpha) dan diperoleh hasil sebagai berikut:

Tabel 5. Hasil Simulasi Antrean

\begin{tabular}{clccc}
\hline Keterangan & $\mathrm{c}=2$ & $\mathrm{c}=3$ & $\mathrm{c}=4$ & $\mathrm{c}=5$ \\
\hline \multicolumn{5}{c}{ Angka kendaraan masuk } \\
\hline Minimum & 181,00 & 180,00 & 181,00 & 181,00 \\
Maksimum & 193,00 & 193,00 & 193,00 & 193,00 \\
Rata-rata & 188,60 & 188,60 & 188,70 & 188,70 \\
\hline \multicolumn{5}{c}{ Angka kendaraan keluar } \\
\hline Minimum & 180,00 & 180,00 & 180,00 & 180,00 \\
Maksimum & 192,00 & 192,00 & 192,00 & 192,00 \\
Rata-rata & 187,60 & 187,60 & 187,70 & 187,90 \\
\hline
\end{tabular}




\begin{tabular}{ccccc}
\hline \multicolumn{5}{c}{ Waktu kendaraan menunggu } \\
\hline Gardu 1 & 19,0044 & 9,4935 & 5,4105 & 3,6720 \\
Gardu 2 & 16,5032 & 12,1495 & 9,5100 & 5,5038 \\
Gardu 3 & - & 11,4763 & 6,5408 & 4,6281 \\
Gardu 4 & - & - & 7,0578 & 4,8080 \\
Gardu 5 & - & - & - & 4,8529 \\
\hline \multicolumn{5}{c}{ Tingkat kesibukan } \\
\hline Gardu 1 & 0,5002 & 0,3288 & 0,2429 & 0,1912 \\
Gardu 2 & 0,4893 & 0,3176 & 0,2550 & 0,2056 \\
Gardu 3 & - & 0,3428 & 0,2435 & 0,1925 \\
Gardu 4 & - & - & 0,2479 & 0,2074 \\
Gardu 5 & - & - & - & 0,1935 \\
\hline
\end{tabular}

\subsubsection{Ukuran Kinerja Sistem Antrean}

Berdasarkan hasil yang diperoleh dengan menggunakan software GUI MATLAB, maka diketahui ukuran-ukuran kinerja sistem antrean Gardu Tol Otomatis Gerbang Tol Muktiharjo. Ukuran kinerja sistem tersebut disajikan pada tabel dan gambar berikut:

Tabel 6. Ukuran Kinerja Sistem Antrean Gardu Tol Otomatis Gerbang Tol Muktiharjo

\begin{tabular}{cccccccc}
\hline $\mathrm{c}$ & $\lambda$ & $\mu$ & $\mathrm{L}_{\mathrm{s}}$ & $\mathrm{L}_{\mathrm{q}}$ & $\mathrm{W}_{\mathrm{s}}$ & $\mathrm{W}_{\mathrm{q}}$ & Po \\
\hline 4 & 191,895 & 191,77 & 25,5646 & 24,5639 & 0,133222 & 0,128007 & 0,367106
\end{tabular}

Berdasarkan Tabel Ukuran Kinerja Sistem Antrean Gardu Tol Otomatis Gerbang Tol Muktiharjo dapat diketahui informasi sebagai berikut:

1. Jumlah tempat pelayanan yang disediakan untuk melayani Gardu tol otomatis adalah empat.

2. Rata-rata jumlah kendaraan yang datang setiap 15 menit adalah $\lambda=191,895$ Artinya, dalam interval waktu 15 menit terdapat rata-rata 191,895 kendaraan yang datang pada antrean Gardu Tol Otomatis Gerbang Tol Muktiharjo

3. Rata-rata jumlah kendaraan yang dilayani setiap 15 menit adalah $\mu=191,765$. Artinya, dalam waktu 15 menit terdapat rata-rata 191,765 kendaraan yang datang untuk dilayani pada antrean Gardu Tol Otomatis Gerbang Tol Muktiharjo

4. Jumlah kendaraan yang diperkirakan di dalam sistem antrean setiap 15 menit adalah $\mathrm{Ls}=25,5646$ kendaraan. Artinya, rata-rata dalam 15 menit total kendaraan yang sedang berada dalam antrean dan kendaraan yang sedang dilayani adalah 25,5646 kendaraan.

5. Jumlah kendaraan yang diperkirakan dalam antrean setiap 15 menit adalah $\mathrm{L}_{\mathrm{q}}=$ 24,5639 kendaraan. Artinya, rata-rata kendaraan dalam 15 menit kendaraan yang menunggu dalam antrean untuk mendapatkan pelayanan adalah 24,5639 kendaraan. 6. Waktu menunggu dalam sistem diperkirakan sebesar $\mathrm{W}_{\mathrm{s}}=0,133222$ dari 15 menit atau sekitar 7,99332 detik.

7. Waktu menunggu yang diperkirakan dalam antrean adalah $\mathrm{W}_{\mathrm{q}}=0,128007$ dari 15 menit atau sekitar 7,68042 detik.

8. Probabilitas bahwa petugas pelayanan menganggur adalah $\mathrm{Po}=0,367106$ yang berarti sistem antrean memiliki peluang sibuk sebesar $63,2894 \%$ dan sisanya $36,7106 \%$ adalah peluang sistem antrean tidak sibuk. 


\section{KESIMPULAN}

Berdasarkan pada pembahasan hasil penelitian yang telah dilakukan, dapat disimpulkan bahwa model sistem antrean kendaraan di Gardu Tol Otomatis Gerbang

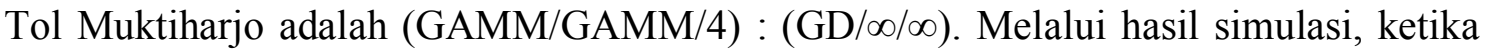
gardu pelayanan yang disediakan adalah 4 diperoleh nilai waktu kendaraan menunggu dalam antrean berada dalam rata-rata 7,1298 detik, tingkat kesibukan tempat pelayanan berada dalam rata-rata $24,73 \%$. Ketika gardu pelayanan yang disediakan adalah 5, nilai waktu menunggu dan tingkat kesibukan juga otomatis akan ikut menurun, namun pembangunan gardu tol otomatis di gerbang tol juga akan menyebabkan bertambahnya perawatan gardu tol itu sendiri dari pihak PT Jasa Marga. Disimpulkan bahwa ketika gardu pelayanan yang disediakan adalah 4 sudah optimal.

\section{DAFTAR PUSTAKA}

Arhami M dan Desiani A. 2005. Pemrograman MATLAB.:Yogyakarta: Andi

Badan Pusat Statitik. 2017. Perkembangan Jumlah Kendaraan Bermotor Menurut Jenis, $\quad 1949-2017 . \quad$ https://www.bps.go.id/linkTableDinamis/view/id/1133. Diakses: 15 Desember 2018

Daniel, W. W. 1989. Statistik Nonparametrik Terapan (terjemahan). Jakarta: PT. Gramedia.

Gross, D. dan Harris, C. M. 1998. Fundamental of Queueing Theory: Third Edition. New York: John Willey and Sons, Inc.

Jasa Marga Semarang. Sekilas Jalan Tol Semarang. http://www. Jasamarga.com/ public/id/infolayanan/toll/ruas.aspx?title=Semarang. Dikases: 15 November 2018

Kakiay, T. J. 2004. Dasar Teori Antrian Untuk Kehidupan Nyata. Yogyakarta: Andi.

Kelton, W. D. 2004. Simulation With Arena: Third Edition. McGraw-Hill, Singapure

Siswanto. 2006, Operations Research, Jilid 2. Jakarta: Erlangga

Subagyo, P. Asri M. dan Handoko T. H. 1992. Dasar-dasar Operation Research. Yogyakarta: BPFE

Taha, H. A. 1996. Riset Operasi, Jilid Dua. Jakarta: Binarupa Aksara.

Walpole, R E and Myers, R. H. 1995. Ilmu Peluang dan Statistika untuk Insinyur dan Ilmuwan, Edisi Keempat. Diterjemahkan oleh: RK Sembiring. Bandung: Penerbit ITB. Terjemahan dari: Probability and Statistics for Engineers and Scientists. 